\title{
Losartan inhibits LPS-induced inflammatory signaling through a PPAR $\gamma$-dependent mechanism in human THP-1 macrophages
}

\begin{abstract}
Jianbo $\mathrm{An}^{1,2}$, Toshiaki Nakajima ${ }^{1,2}$, Keiji $\mathrm{Kuba}^{2,3,4}$ and Akinori Kimura ${ }^{1,2}$
Macrophages have critical roles in the pathogenesis of atherosclerosis by activating the innate immune system and producing inflammatory cytokines. Accumulating evidence indicates that angiotensin type 1 receptor (AT1R) blockers exert antiinflammatory effects in inflammatory diseases including atherosclerosis. In this study, we investigated the effect of losartan, an AT1R blocker, on the proinflammatory gene expression induced by bacterial lipopolysaccharide (LPS) in a well-defined in vitro human THP-1 macrophage system. We found that losartan significantly attenuated the LPS-induced expression of proinflammatory genes TNF- $\alpha$, IL-8 and COX-2. However, exogenous angiotensin II (AngII) had no effect on LPS-induced inflammatory signaling despite the expression of AT1R. In addition, losartan did not block LPS-induced IKB phosphorylation, which is downstream of Toll-like receptor activation. Peroxisome proliferator-activated receptor-gamma (PPAR $\gamma$ ) antagonists, GW9662 and T0070907, reversed the inhibitory effects of losartan on LPS-induced TNF- $\alpha$ and IL- 8 expression in THP-1 macrophages. These observations suggest that losartan inhibits LPS-induced proinflammatory gene expression in macrophages by activating the PPAR $\gamma$ pathway rather than by the competitive inhibition of AT1R binding to Angll.

Hypertension Research (2010) 33, 831-835; doi:10.1038/hr.2010.79; published online 27 May 2010
\end{abstract}

Keywords: inflammatory cytokine; losartan; LPS; macrophage; PPAR $\gamma$

\section{INTRODUCTION}

Atherosclerosis comprises a series of highly specific cellular and molecular inflammatory responses. ${ }^{1}$ It is widely accepted that enhanced renin-angiotensin system (RAS) signaling contributes to the inflammatory reactions in atherosclerosis. ${ }^{2,3}$ Angiotensin II (AngII) stimulates the expression of inflammatory cytokines and chemokines, which are tightly linked to endothelial cell dysfunction, inflammatory cell infiltration and vascular smooth muscle cell migration. Through its binding to the angiotensin type 1 receptor (AT1R), AngII activates multiple intracellular signaling pathways, including G protein-coupled, mitogen-activated protein kinase, and non-receptor tyrosine kinase pathways. These signaling pathways are involved in AngII-induced cytokine and chemokine expression. ${ }^{4}$

Accumulating evidence indicates that the Toll-like receptor (TLR)signaling pathways also play a crucial role in the initiation and progression of atherosclerosis. ${ }^{5-7}$ In addition, TLRs are expressed in infiltrating macrophages, endothelial cells and vascular smooth muscle cells in advanced atherosclerotic lesions, which might contribute to plaque activation. Different TLRs recognize a variety of molecules, including lipids and nucleic acids. On binding the ligand, TLRs recruit adaptor proteins to the cytoplasmic signaling domain, the Toll/ interleukin-1 (IL-1) receptor domain, resulting in the activation of signaling cascades to produce proinflammatory cytokines and chemokines. ${ }^{8}$

It was reported that the proinflammatory effect of AngII in vascular smooth muscle cells involved the TLR4 pathway. ${ }^{9}$ In addition, AT1R blockers exerted anti-inflammatory effects to suppress the inflammatory response induced by a TLR4 ligand, lipopolysaccharide (LPS). ${ }^{10,11}$ These lines of evidence suggested that RAS would interact with TLR-signaling pathways during the inflammatory reaction of atherosclerosis. To clarify this point, we investigated the effect of the AT1R blocker losartan on the LPS-induced inflammatory reaction that is linked to the TLR4-signaling pathway in macrophages because the macrophages and the inflammatory cytokines they produce are crucial to the pathogenesis of atherosclerosis. ${ }^{1}$ We focused on three proinflammatory genes, $T N F-\alpha, I L-8$ and $C O X-2$, which are expressed under the control of the LPS-TLR4 pathway. It was found that losartan exerted anti-inflammatory effects on the LPS-induced reactions, but these effects seemed to be independent from the antagonistic function to AT1R. We report here that losartan inhibits LPS-induced inflammatory signals through a peroxisome proliferatoractivated receptor-gamma (PPAR $\gamma)$-dependent process in a human monocyte/macrophage cell line, THP-1.

${ }^{1}$ Laboratory of Genome Diversity, Graduate School of Biomedical Science, Medical Research Institute, Tokyo Medical and Dental University, Tokyo, Japan; ${ }^{2}$ Department of Molecular Pathogenesis, Medical Research Institute, Tokyo Medical and Dental University, Tokyo, Japan; ${ }^{3}$ MTT Program, Medical Research Institute, Tokyo Medical and Dental University, Tokyo, Japan and ${ }^{4}$ Department of Biological Informatics and Experimental Therapeutics, Akita University Graduate School of Medicine, Akita, Japan

Correspondence: Professor A Kimura, Department of Molecular Pathogenesis, Medical Research Institute, Tokyo Medical and Dental University, 1-5-45 Yushima, Bunkyo-ku, Tokyo 113-8510, Japan.

E-mail: akitis@mri.tmd.ac.jp

Received 5 November 2009; revised 18 March 2010; accepted 31 March 2010; published online 27 May 2010 


\section{METHODS}

\section{Cell culture}

The human THP-1 cell line (American Type Culture Collection, Manassas, VA, USA) was cultured in RPMI-1640 (Sigma, St Louis, MO, USA) medium containing $10 \%$ fetal calf serum (FCS) (Nichirei, Tokyo, Japan) and $1 \%$ penicillin/streptomycin (P/S) (Gibco, Grand Island, NY, USA) at $37{ }^{\circ} \mathrm{C}$ in a humidified atmosphere of $5 \% \mathrm{CO}_{2}$. To induce macrophage differentiation, THP- 1 monocytes were seeded at a density of $5 \times 10^{5}$ cells per $\mathrm{ml}$ in a six-well plate or a 10-cm dish and treated with $200 \mathrm{~nm}$ phorbol 12-myristate 13-acetate (PMA) (Calbiochem, San Diego, CA, USA) for $48 \mathrm{~h}$. After the incubation, nonadherent cells and PMA were aspirated and the adherent cells, which resembled mature macrophages, were washed twice with RPMI-1640 medium without FCS and P/S. THP-1 macrophages were then incubated in RPMI-1640 medium without FCS and P/S overnight using a serum starvation condition. AngII (Sigma), LPS (Salmonella, Sigma), losartan (LKT Laboratories, St Paul, MN, USA), GW9662 (Sigma) and T0070907 (Sigma) were diluted with phosphate-buffered saline (Gibco) or dimethylsulphoxide (Sigma) and applied to the THP-1 macrophages at the concentrations indicated in the text and figures.

\section{Analysis of mRNA expression}

Total RNA was extracted from the treated or untreated THP-1 macrophages using Trizol reagent (Invitrogen, Carlsbad, CA, USA) according to the manufacturer's recommendations. Complementary DNA (cDNA) was synthesized by reverse transcription (RT) from $1 \mu \mathrm{g}$ of RNA using the PrimeScript RT reagent kit (Takara, Tokyo, Japan) according to the manufacturer's protocol. The cDNA was used as the template in a RT-PCR to analyze the gene expression of angiotensinogen, renin, angiotensin-converting enzyme (ACE), $I L-8, T N F-\alpha$ and COX-2. Quantitative RT-PCR analysis was carried out using SYBR Premix Ex Taq (Takara). Relative quantification was carried out using the comparative Ct method, and glyceraldehyde-3-phosphate dehydrogenase served as the control. The sequences of the oligonucleotide primers used in the RT-PCR analyses are available on request.

\section{Immunoblotting analysis}

Cultured cells in the 10-cm dish were washed twice with phosphate-buffered saline and lysed using prechilled lysis buffer (20 mM Tris- $\mathrm{HCl}, 150 \mathrm{~mm} \mathrm{NaCl}$,
$5 \mathrm{~mm}$ EDTA and 1\% Triton) containing a protease inhibitor cocktail (Sigma). When the phosphorylation status was examined, $5 \mathrm{~mm} \mathrm{NaF}$ and $2 \mathrm{~mm} \mathrm{Na}_{3} \mathrm{VO}_{4}$ were added to prevent protein dephosphorylation. After measuring the protein concentration using the bicinchoninic acid (BCA) protein assay reagent (Pierce Biotechnology, Rockford, IL, USA), equal concentrations of protein diluted in $2 \times$ Laemmli buffer ( $50 \mathrm{~mm}$ Tris-HCl, $150 \mathrm{~mm} \mathrm{NaCl}, 10 \%$ Gly, $4 \%$ SDS) were separated by SDS polyacrylamide gel electrophoresis and then transferred to a nitrocellulose membrane (Invitrogen). Nonspecific binding was blocked by preincubating the membrane in $5 \%$ skim milk (BD, Sparks, MD, USA) in a TBS $0.1 \%$ Tween 20 (Wako, Osaka, Japan) solution. Subsequently, the membrane was incubated with primary antibodies against AT1R (1:200) (Santa Cruz Biotechnology, Santa Cruz, CA, USA), glyceraldehyde-3-phosphate dehydrogenase (1:200) (Santa Cruz Biotechnology), phospho-ІкB (1:1000) (Cell Signaling Technology, Danvers, MA, USA) or total-IкB (1:1000) (Cell Signaling Technology), and were then incubated with secondary rabbit anti-mouse or goat anti-rabbit IgG horseradish peroxidase-conjugated antibodies (1:1000) (Dako, Tokyo, Japan). Signals on the membrane were visualized by chemiluminescence (Image Reader LAS-3000; Fujifilm, Tokyo, Japan), and their densities were quantified using MultiGauge Ver. 3.1 (Fujifilm, Tokyo, Japan).

\section{Statistical analysis}

Bar graph data are expressed as means \pm s.d. Statistical comparisons were carried out using one-way analysis of variance followed by a post hoc Tukey's or Dunnett's multiple comparison tests. The results were considered statistically significant if the $P$ value was $<0.05$.

\section{RESULTS}

Losartan inhibits LPS-induced expression of proinflammatory genes The effect of the AT1R antagonist losartan on the LPS-induced expression of proinflammatory genes in the THP-1 cell line was evaluated by a quantitative RT-PCR method. THP- 1 cells were treated with PMA to differentiate from a monocyte-like phenotype to a macrophage-like phenotype, and after $3 \mathrm{~h}$ of treatment with LPS, the steady-state mRNA levels of TNF- $\alpha, I L-8$ and COX-2 were investigated in THP-1 macrophages. As shown in Figures 1a-c, LPS induced the expression of TNF- $\alpha, I L-8$ and $C O X-2$, and pretreatment
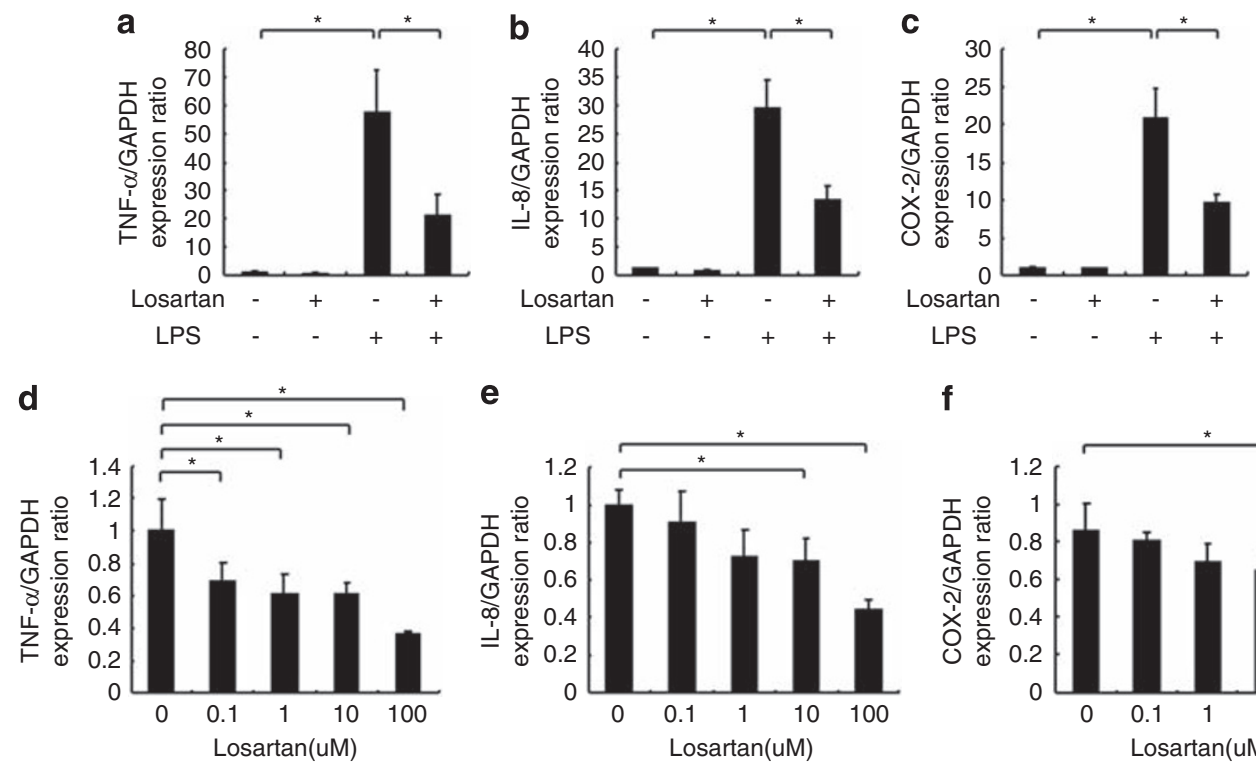

e
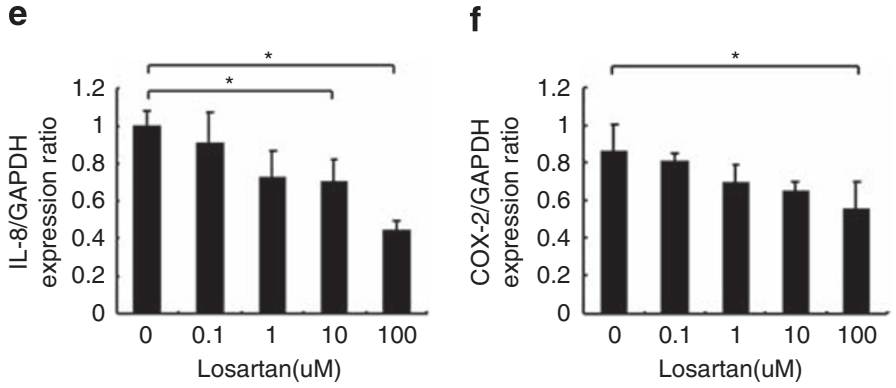

Figure 1 Effects of losartan on LPS-induced expression of proinflammatory genes in THP-1 macrophages. The effects of losartan ( $100 \mu \mathrm{m}, 3 \mathrm{~h}$ ) on TNF- $\alpha$ (a), IL-8 (b) and COX-2 (c) expression was measured in LPS-unstimulated and -stimulated ( $\left.1 \mu \mathrm{g} \mathrm{ml} \mathrm{I}^{-1}\right)$ THP-1 macrophages by quantitative RT-PCR. The data are represented as mean \pm s.d. ( $n=3$ for each case, repeated twice). ${ }^{*} P<0.05$. Dose-dependent effects of losartan on $T N F-\alpha$ (d), IL-8 (e) and COX-2 (f) expression were investigated in LPS-stimulated $\left(1 \mu \mathrm{g} \mathrm{m} l^{-1}\right)$ THP-1 macrophages by quantitative RT-PCR and indicated as mean $\pm \mathrm{s}$.d. ( $n=3$ for each case, repeated twice). ${ }^{*} P<0.05$. Four doses of losartan $(0.1,1,10$ and $100 \mu \mathrm{M})$ were tested and the linear correlation coefficient was calculated; $R^{2}=0.461$, $P<0.05$ for (d); $R^{2}=0.550, P<0.05$ for (e); and $R^{2}=0.487, P<0.05$ for (f). 
with losartan attenuated the LPS-induced expression of these proinflammatory genes. The decreased expression levels of $T N F-\alpha, I L-8$ and $C O X-2$ were related to the concentration of losartan in a dosedependent manner (Figures $1 \mathrm{~d}-\mathrm{f}$, respectively).

\section{Expression of RAS component genes}

We evaluated the expression of RAS components such as angiotensinogen, renin, ACE and AT1R in THP-1 macrophages. The expression of AT1R was detected at the protein level (Figure 2a). On the other hand, except for angiotensinogen, the expression of RAS components essential for the production of AngII could not be detected at the mRNA level (Figure 2b). In addition, LPS did not change the expression of the RAS components (Figure 2). These data suggest that the AngII autocrine pathway did not exist in THP-1 macrophages.

\section{Effects of AngII on expression levels of proinflammatory genes}

The inhibitory effects of losartan on LPS-induced inflammatory responses prompted us to investigate whether AngII-AT1R activation would enhance LPS-induced signaling. The effect of AngII on the expression of proinflammatory genes was analyzed using quantitative RT-PCR $12 \mathrm{~h}$ after treatment with AngII in the presence or absence of LPS. As demonstrated in Figure 3, AngII showed no additive effects on LPS-induced proinflammatory gene expression. In addition, AngII alone had no effect on proinflammatory gene expression. These observations suggest that AngII-AT1R activation does not affect LPS-induced inflammatory responses.

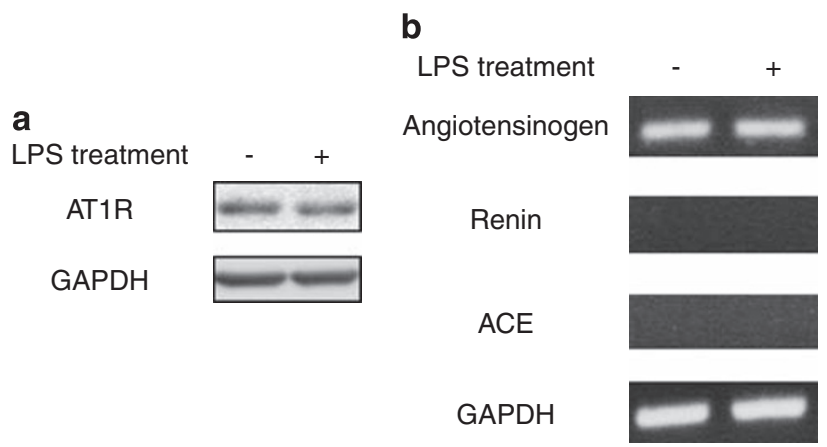

Figure 2 Expression of RAS components in THP-1 macrophages. (a) Expression of AT1R in LPS-untreated and -treated $\left(1 \mu \mathrm{gml}^{-1}\right)$ THP-1 macrophages at the protein level as detected by immunoblotting. (b) Expression of RAS components involved in the production of Angll in LPSuntreated or -treated $\left(1 \mu \mathrm{gml}^{-1}\right)$ THP-1 macrophages at the mRNA level as detected by RT-PCR.
Effects of losartan on LPS-induced phosphorylation of IкB

It is widely accepted that the I $\mathrm{K}-\mathrm{I} \kappa \mathrm{B}-\mathrm{NF} \kappa \mathrm{B}$ activation pathway has a central role in proinflammatory gene expression downstream of the LPS-TLR4 pathway. ${ }^{8}$ To further dissect the mechanism of losartanmediated inhibition of LPS-induced inflammatory signals, we asked whether losartan would inhibit a downstream signal of the LPS-TLR4 pathway, that is, I $\mathrm{B}$ phosphorylation. As indicated in Figure 4, LPS induced the phosphorylation of I $\mathrm{KB}$, and losartan did not attenuate this phosphorylation.

\section{Effects of losartan and PPAR $\gamma$ antagonists on LPS-induced} proinflammatory gene expression

As AT1R blockers have recently been implicated as functional agonists of $\operatorname{PPAR} \gamma,{ }^{12}$ we investigated whether losartan would exert anti-inflammatory effects as a PPAR $\gamma$ agonist in our experimental macrophage system. We used two different PPAR $\gamma$ antagonists, GW9662 and T0070907, in studying the effects on LPS-induced proinflammatory gene expression. Treatment with GW9662 or T0070907 significantly counteracted the inhibitory effects of losartan on TNF- $\alpha$ and $I L-8$ expression, whereas GW9662 or T0070907 alone had no effect on LPS-induced proinflammatory gene expression (Figures $5 \mathrm{a}, \mathrm{b}, \mathrm{d}$ and $\mathrm{e}$ ). In addition, cotreatment of losartan with GW9662 or T0070907 did not affect the LPS-induced IкB phosphorylation level (Figure 4). On the other hand, the effect of these PPAR $\gamma$ antagonists against losartan was not observed for $\mathrm{COX}-2$ expression (Figures $5 \mathrm{c}$ and $\mathrm{f}$ ). These findings suggest that losartan attenuates

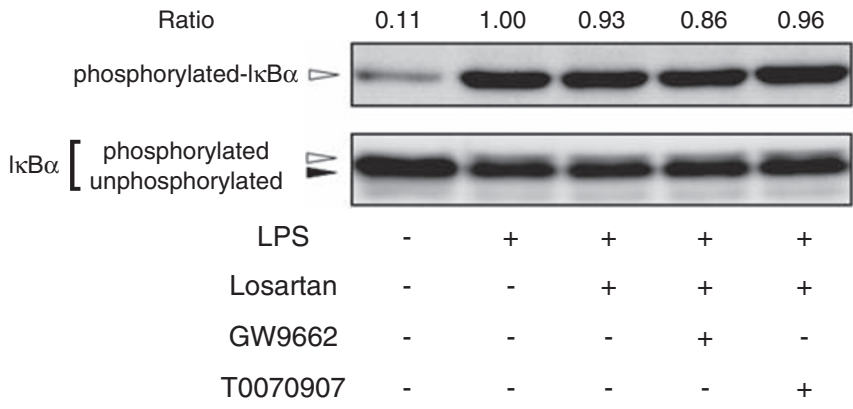

Figure 4 Effect of losartan on LPS-induced $1 \kappa B$ phosphorylation in THP-1 macrophages. The amounts of phosphorylated $I_{\kappa} B$ in the vehicle control, LPS-treated $\left(1 \mu \mathrm{g} \mathrm{ml}^{-1}, 1 \mathrm{~h}\right)$, LPS+losartan $(100 \mu \mathrm{m}, 1 \mathrm{~h})$, LPS+losartan+ GW9662 $(10 \mu \mathrm{m}, 1 \mathrm{~h})$ and LPS+losartan+T0070907 $(1 \mu \mathrm{m}, 1 \mathrm{~h})$ groups of THP-1 macrophages were analyzed at the protein level by immunoblotting. The ratio of phosphorylated $I \kappa B$ to total $I \kappa B$ was empirically calculated and represented as a numerical value (repeated three times).
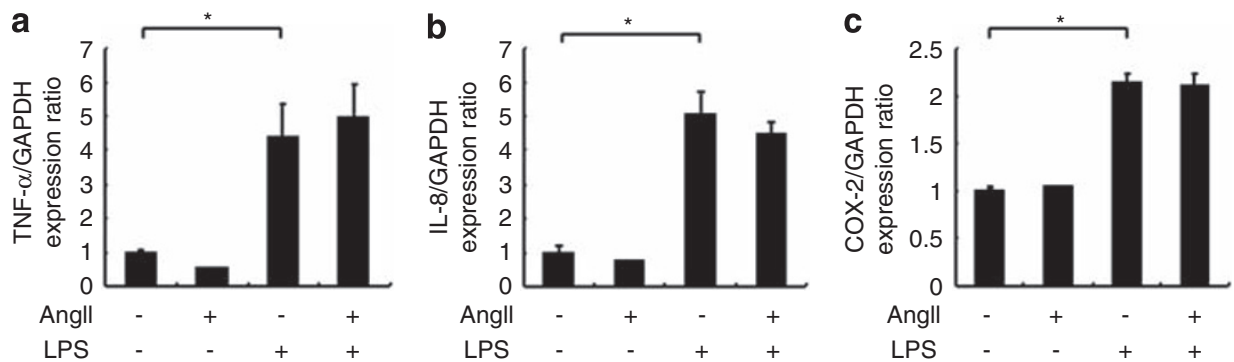

Figure 3 Effects of Angll on the expression of proinflammatory genes in THP-1 macrophages. Effect of Angll $\left(10^{-7} \mathrm{M}, 12 \mathrm{~h}\right)$ on $T N F-\alpha(\mathbf{a}), / L-8(\mathbf{b})$ and $C O X$ 2 (c) expression was measured in LPS-unstimulated and -stimulated $\left(1 \mu \mathrm{g} \mathrm{ml}^{-1}\right)$ THP-1 macrophages by quantitative RT-PCR. The data are represented as mean \pm s.d. ( $n=3$ for each case, repeated twice). ${ }^{*} P<0.05$. 

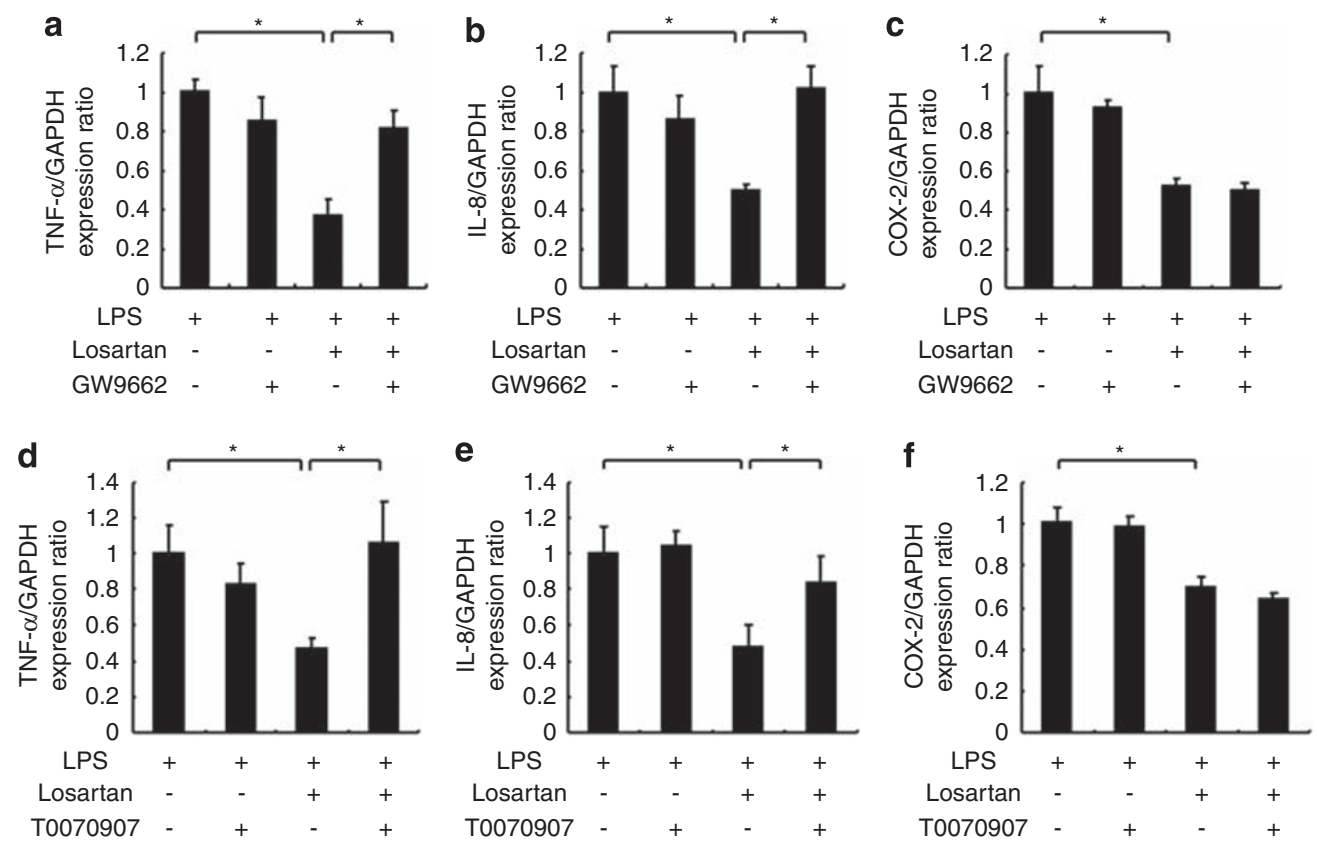

Figure 5 Effect of losartan in the presence or absence of PPAR $\gamma$ antagonists on LPS-induced expression of proinflammatory genes in THP-1 macrophages. The effect of GW9662 $(10 \mu \mathrm{m}, 3 \mathrm{~h}, \mathbf{a}-\mathbf{c})$ or T0070907 $(1 \mu \mathrm{m}, 3 \mathrm{~h}, \mathbf{d}-\mathbf{f})$ coupled with or without losartan $(100 \mu \mathrm{m})$ in LPS-treated $\left(1 \mu \mathrm{gml}{ }^{-1}\right)$ THP-1 macrophages on $T N F-\alpha(\mathbf{a}, \mathbf{d}), I L-8(\mathbf{b}, \mathbf{e})$ and $\operatorname{COX}-2(\mathbf{c}, \mathbf{f})$ expression was measured by quantitative RT-PCR. The data are represented as mean \pm s.d. $(n=3$ for each case, repeated twice). ${ }^{*} P<0.05$.

LPS-induced proinflammatory gene expression at least in part by acting as a PPAR $\gamma$ agonist.

\section{DISCUSSION}

We detected no interaction between RAS and the LPS-TLR4 inflammatory signaling pathway in human THP-1 macrophages in this study. Although losartan induced anti-inflammatory effects, it did so independent of its antagonistic role against AT1R, because AngII showed no effect on proinflammatory gene expression. Surprisingly, AngII itself had little effect on inflammatory gene expression despite the expression of AT1R in THP-1 macrophages. It has been reported that AngII induced inflammatory gene expression in endothelial cells, vascular smooth muscle cells and blood vessel tissues. ${ }^{4}$ The reason why AngII does not induce proinflammatory gene expression in THP-1 macrophages remains unknown, but the concentration of AngII used is not likely to be a factor because we tested a wide range of dose-dependent effects. Nevertheless, our results show that THP-1 macrophages lack the essential components to produce AngII, suggesting that AngII was not produced by the macrophages themselves and that the RAS was not involved in the inhibitory effect of losartan in THP-1 macrophages. These findings are in good agreement with those of the recent reports showing that another AT1R blocker, candesartan, reduced the LPS-induced innate immune response by a mechanism that is unrelated to AT1R inhibition. ${ }^{13,14}$

In this study, we used a high concentration $(100 \mu \mathrm{M})$ of losartan, which was far from a physiological concentration in vivo, calling into question the significance of our findings. However, we demonstrated the dose-dependent effects of losartan on LPS-induced inflammatory gene expression in THP-1 macrophages (Figures 1d-f). These observations suggest that losartan could suppress the inflammatory signals at even lower concentrations, although the effects would be small at physiological concentrations in vivo.
We investigated the effect of losartan on LPS-induced phosphoryla-

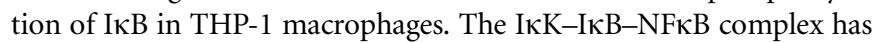
an essential role in proinflammatory gene expression, and the TLR signaling is the main inducer of I $\mathrm{KK}-\mathrm{I} \kappa \mathrm{B}-\mathrm{NF} \kappa \mathrm{B}$ activation. I KK phosphorylates $\mathrm{I} \kappa \mathrm{B}$, leading to degradation, which allows free NFKB to translocate into the nucleus and regulates the transcription of target genes, including inflammatory cytokines and chemokines. ${ }^{8}$ We speculated that the inhibitory effects of losartan on LPS-induced proinflammatory gene expression were mediated by I $\mathrm{KK}-\mathrm{I} \kappa \mathrm{B}-\mathrm{NF} \kappa \mathrm{B}$ signaling because studies showed that AT1R blockers exerted antiinflammatory effects by suppressing I $\mathrm{KK}-\mathrm{I} \kappa \mathrm{B}-\mathrm{NF} \kappa \mathrm{B}$ activation. ${ }^{15,16}$ However, our data show that losartan has no effect on LPS-induced I $\mathrm{B}$ phosphorylation, suggesting that losartan does not inhibit LPSinduced signaling through the IкK-ІкB-NFкB pathway, at least at the level of NF- $\kappa \mathrm{B}$ activation.

Recently, functions for AT1R blockers other than antagonizing AT1R have been reported. For instance, EXP3179, an active metabolite of losartan synthesized by the cytochrome P450 pathway, shows structural homology with indomethacin, a COX inhibitor, which inhibits the COX-2-dependent activation of thromboxane A2 and prostaglandin F2 $\alpha .{ }^{17}$ EXP3179 has also been reported to have a distinct activity as a PPAR $\gamma$ agonist. ${ }^{12,18}$ In addition, another AT1R blocker, telmisartan, has structural similarity to PPAR $\gamma$ agonists and is reported to affect glucose and lipid metabolism in the same manner as PPAR $\gamma$ agonists. ${ }^{19}$

It has been reported that the activated $\operatorname{PPAR} \gamma$-signaling pathway inhibits proinflammatory gene expression in macrophages. ${ }^{20,21}$ In this study, we investigated the effects of two different PPAR $\gamma$ antagonists, GW9662 and T0070907, on LPS-induced proinflammatory gene expression. Although GW9662 and T0070907 themselves had no effect, these antagonists counteracted the inhibitory effects of losartan on TNF- $\alpha$ and $I L-8$ expression. Although it was not evident whether a cytochrome P450 pathway could synthesize the metabolite EXP3179 
in THP-1 macrophages, the expression of cytochrome P450 isoenzymes, 2C9 and 3A4, which are linked to losartan metabolism, is well defined in the lineage of monocytes/macrophages. ${ }^{22,23}$ Alternatively, it was reported that losartan itself could serve as a PPAR $\gamma$ agonist, ${ }^{12}$ supporting the idea that losartan attenuates LPS-induced proinflammatory gene expression by acting as a PAR $\gamma$ agonist.

In this study, we did not use other AT1R blockers with strong $\operatorname{PPAR} \gamma$ activity, such as telmisartan and irbesartan, or PPAR $\gamma$ agonists, such as glitazone, to demonstrate the involvement of the PPAR $\gamma$ pathway because we wanted to clarify the interaction between RAS and TLR-signaling pathways in macrophages. In addition, the direct use of PPAR $\gamma$ agonists might be problematic because of their antiinflammatory effects, which can act, at least in part, through PPAR $\gamma$ independent mechanisms. ${ }^{24}$ Instead, we evaluated two different $\operatorname{PPAR} \gamma$ antagonists on losartan-induced anti-inflammatory gene expression to demonstrate the PPAR $\gamma$ agonistic effects of losartan. Importantly, the effects of GW9662 and T0070907 against losartan were independent of the I $\kappa \mathrm{K}-\mathrm{I} \kappa \mathrm{B}-\mathrm{NF} \kappa \mathrm{B}$ activation pathway. These results were consistent with the reports that PPAR $\gamma$ agonists repress the expression of inflammatory genes through NF- $\kappa \mathrm{B} / \mathrm{IRF}-\mathrm{indepen-}$ dent mechanisms. In addition, PPAR $\gamma$ was reported to affect the mRNA stability of inflammatory genes without interfering with the NF- $\kappa \mathrm{B}$ complex. ${ }^{25,26}$ However, it should be noted here that COX-2 expression was still reduced after being treated with GW9662 or T0070907. In fact, losartan or its metabolite EXP3179 could also function as a thromboxane A2 receptor blocker and COX inhibitor, ${ }^{27}$ implying that other regulatory mechanisms might be involved in the losartan-mediated suppression of LPS-induced inflammatory signaling.

In conclusion, RAS did not have a crucial role in LPS-induced proinflammatory gene expression in the human THP-1 macrophage system. We demonstrated that losartan inhibits LPS-induced proinflammatory gene expression through a PPAR $\gamma$-dependent pathway, and this effect is independent of its antagonistic action against AT1R.

\section{ACKNOWLEDGEMENTS}

This study was supported in part by grants-in-aid from the Ministry of Education, Culture, Sports, Science and Technology, Japan, grants for Japan-Korea collaboration research programs from the Japan Society for the Promotion of Science, grants for the Founding Research Centers for Emerging and Reemerging Infectious Diseases program, and research grants from the Ministry of Health, Labour and Welfare, Japan, and the Institute of Seizon and Life Sciences.

1 Ross R. Atherosclerosis-an inflammatory disease. N Engl J Med 1999; 340: 115-126.

2 Warnholtz A, Nickenig G, Schulz E, Macharzina R, Bräsen JH, Skatchkov M, Heitzer T, Stasch JP, Griendling KK, Harrison DG, Böhm M, Meinertz T, Münzel T. Increased $\mathrm{NADH}$-oxidase-mediated superoxide production in the early stages of atherosclerosis: evidence for involvement of the renin-angiotensin system. Circulation 1999; 99: 2027-2033.

3 Toko H, Zou Y, Minamino T, Masaya M, Harada M, Nagai T, Sugaya T, Terasaki F, Kitaura Y, Komuro I. Angiotensin II type 1a receptor is involved in cell infiltration, cytokine production, and neovascularization in infarcted myocardium. Arterioscler Thromb Vasc Biol 2004; 24: 664-670.

4 Mehta PK, Griendling KK. Angiotensin II cell signaling: physiological and pathological effects in the cardiovascular system. Am J Physiol Cell Physiol 2007; 292: C82-C97.
5 Edfeldt K, Swedenborg J, Hansson GK, Yan ZQ. Expression of toll-like receptors in human atherosclerotic lesions: a possible pathway for plaque activation. Circulation 2002; 105: 1158-1161.

$6 \mathrm{Xu} \mathrm{XH,} \mathrm{Shah} \mathrm{PK,} \mathrm{Faure} \mathrm{E,} \mathrm{Equils} \mathrm{O,} \mathrm{Thomas} \mathrm{L,} \mathrm{Fishbein} \mathrm{MC,} \mathrm{Luthringer} \mathrm{D,} \mathrm{Xu} \mathrm{XP,}$ Rajavashisth TB, Yano J, Kaul S, Arditi M. Toll-like receptor-4 is expressed by macrophages in murine and human lipid-rich atherosclerotic plaques and upregulated by oxidized LDL. Circulation 2001; 104: 3103-3108.

7 Shinohara M, Hirata K, Yamashita T, Takaya T, Sasaki N, Shiraki R, Ueyama T, Emoto N, Inoue N, Yokoyama M, Kawashima S. Local overexpression of toll-like receptors at the vessel wall induces atherosclerotic lesion formation: synergism of TLR2 and TLR4. Arterioscler Thromb Vasc Biol 2007; 27: 2384-2391.

8 Kawai T, Akira S. TLR signaling. Semin Immunol 2007; 19: 24-32.

9 Ji Y, Liu J, Wang Z, Liu N. Angiotensin II induces inflammatory response partly via toll-like receptor 4-dependent signaling pathway in vascular smooth muscle cells. Cell Physiol Biochem 2009; 23: 265-276.

10 Lund DD, Brooks RM, Faraci FM, Heistad DD. Role of angiotensin II in endothelial dysfunction induced by lipopolysaccharide in mice. Am J Physiol Heart Circ Physiol 2007; 293: H3726-H3731.

11 Sanchez-Lemus E, Murakami Y, Larrayoz-Roldan IM, Moughamian AJ, Pavel J, Nishioku T, Saavedra JM. Angiotensin II AT1 receptor blockade decreases lipopolysaccharide-induced inflammation in the rat adrenal gland. Endocrinology 2008; 149 . 5177-5188

12 Schupp M, Janke J, Clasen R, Unger T, Kintscher U. Angiotensin type 1 receptor blockers induce peroxisome proliferator-activated receptor-gamma activity. Circulation 2004; 109: 2054-2057.

13 Larrayoz IM, Pang T, Benicky J, Pavel J, Sánchez-Lemus E, Saavedra JM. Candesartan reduces the innate immune response to lipopolysaccharide in human monocytes. $J$ Hypertens 2009; 27: 2365-2376.

14 Chen S, Ge Y, Si J, Rifai A, Dworkin LD, Gong R. Candesartan suppresses chronic renal inflammation by a novel antioxidant action independent of AT1R blockade. Kidney Int 2008; 74: 1128-1138.

15 Dandona P, Kumar V, Aljada A, Ghanim H, Syed T, Hofmayer D, Mohanty P, Tripathy D, Garg R. Angiotensin II receptor blocker valsartan suppresses reactive oxygen species generation in leukocytes, nuclear factor-kappa B, in mononuclear cells of normal subjects: evidence of an antiinflammatory action. J Clin Endocrinol Metab 2003; 88: 4496-4501.

16 Yamashita C, Hayashi T, Mori T, Tazawa N, Kwak CJ, Nakano D, Sohmiya K, Okada Y, Kitaura Y, Matsumura Y. Angiotensin II receptor blocker reduces oxidative stress and attenuates hypoxia-induced left ventricular remodeling in apolipoprotein E-knockout mice. Hypertens Res 2007; 30: 1219-1230.

17 Krämer C, Sunkomat J, Witte J, Luchtefeld M, Walden M, Schmidt B, Tsikas D, Böger $\mathrm{RH}$, Forssmann WG, Drexler H, Schieffer B. Angiotensin II receptor-independent antiinflammatory and antiaggregatory properties of losartan: role of the active metabolite EXP3179. Circ Res 2002; 90: 770-776.

18 Schupp M, Lee LD, Frost N, Umbreen S, Schmidt B, Unger T, Kintscher U. Regulation of peroxisome proliferator-activated receptor gamma activity by losartan metabolites. Hypertension 2006; 47: 586-589.

19 Benson SC, Pershadsingh $\mathrm{HA}$, $\mathrm{Ho} \mathrm{Cl}$, Chittiboyina A, Desai P, Pravenec M, Qi N, Wang J, Avery MA, Kurtz TW. Identification of telmisartan as a unique angiotensin II receptor antagonist with selective PPARgamma-modulating activity. Hypertension 2004; 43: 993-1002.

20 Jiang C, Ting AT, Seed B. PPAR-gamma agonists inhibit production of monocyte inflammatory cytokines. Nature 1998; 391: 82-86.

21 Ricote M, Li AC, Willson TM, Kelly CJ, Glass CK. The peroxisome proliferator-activated receptor-gamma is a negative regulator of macrophage activation. Nature 1998; 391 : 79-82.

22 Hodges VM, Molloy GY, Wickramasinghe SN. Demonstration of mRNA for five species of cytochrome P450 in human bone marrow, bone marrow-derived macrophages and human haemopoietic cell lines. Br J Haematol 2000; 108: 151-156.

23 Sieben S, Baron JM, Blömeke B, Merk HF. Multiple cytochrome P450-isoenzymes mRNA are expressed in dendritic cells. Int Arch Allergy Immunol 1999; 118: 358-361.

24 Chawla A, Barak Y, Nagy L, Liao D, Tontonoz P, Evans RM. PPAR-gamma dependent and independent effects on macrophage-gene expression in lipid metabolism and inflammation. Nat Med 2001; 7: 48-52.

25 Ogawa S, Lozach J, Benner C, Pascual G, Tangirala RK, Westin S, Hoffmann A, Subramaniam S, David M, Rosenfeld MG, Glass CK. Molecular determinants of crosstalk between nuclear receptors and toll-like receptors. Cell 2005; 122: 707-721.

26 Moon Y, Yang H, Park SH. Hypo-responsiveness of interleukin-8 production in human embryonic epithelial intestine 407 cells independent of NF-kappaB pathway: new lessons from endotoxin and ribotoxic deoxynivalenol. Toxicol Appl Pharmacol 2008; 231: 94-102.

27 Sadoshima J. Novel AT1 receptor-independent functions of losartan. Circ Res 2002; 90: 754-756. 